Poster sessions

Abstract P265 Table 1 Characteristics and biomarker assessment of CTEPH and control subjects

\begin{tabular}{|c|c|c|c|c|c|c|}
\hline & \multicolumn{2}{|c|}{ CTEPH Pre PEA } & \multicolumn{2}{|c|}{ CTEPH Post PEA } & \multicolumn{2}{|c|}{ Healthy controls } \\
\hline & Median & $95 \% \mathrm{Cl}$ & Median & $95 \% \mathrm{Cl}$ & Median & $95 \% \mathrm{Cl}$ \\
\hline Age & 63.59 & $58.6-66.2$ & 64.09 & $60.98-66.59$ & 60.64 & $58.00-61.46$ \\
\hline IL6 (pg/ml) & 0.13 & $0.13-0.13$ & 0.13 & $0.13-0.13$ & 0.13 & $0.13-0.13$ \\
\hline IL8 (pg/ml) ${ }^{\mathrm{f}}$ & 7.22 & $4.76-9.34$ & 4.12 & $1.84-5.68$ & 0.13 & $0.13-1.94$ \\
\hline IL10 $(\mathrm{pg} / \mathrm{ml})^{\mathrm{fS}}$ & 1.85 & $1.29-2.96$ & 1.44 & $0.91-2.18$ & 0.13 & $0.13-0.20$ \\
\hline $\mathrm{TNF} \alpha(\mathrm{pg} / \mathrm{ml})^{\mathrm{f \$}}$ & 9.69 & $7.89-11.10$ & 9.21 & $6.46-10.91$ & 4.72 & $0.45-6.03$ \\
\hline hs CRP $(p g / m l)^{f}$ & 2.86 & $2.23-3.91$ & & & 0.72 & $0.62-2.01$ \\
\hline VEGFa (pg/ml) & 157.68 & $121.21-244.79$ & 142.37 & $53.71-178.69$ & 36.78 & $13.70-167.42$ \\
\hline VEGFc $(p g / m l)^{\mathbb{E} \$}$ & 21.96 & $8.71-35.73$ & 17.10 & $9.33-25.14$ & 54.22 & $49.25-62.74$ \\
\hline VEGFd (pg/ml) & 30.51 & $6.90-50.36$ & 27.72 & $8.93-38.97$ & 86.18 & $36.16-108.62$ \\
\hline Ang2 $(\mathrm{pg} / \mathrm{ml})^{* \mathrm{f}}$ & 1266.79 & $1079.31-1649.42$ & 757.07 & $545.04-922.97$ & 575.99 & $539.78-642.32$ \\
\hline BMP9 (pg/ml) & 25.47 & $18.13-28.79$ & 24.87 & $18.49-33.77$ & 29.56 & $16.63-40.97$ \\
\hline Endoglin $(\mathrm{pg} / \mathrm{ml})^{*}$ & 242.30 & $209.53-285.24$ & 117.22 & $34.50-160.43$ & 61.71 & $27.40-247.32$ \\
\hline ProBNP (pg/ml) & 575.00 & $130.1-1142$ & 234.00 & $195.50-270.00$ & & \\
\hline RAP $(m m H g)$ & 8.00 & $7.00-9.00$ & 7.00 & $6.00-8.00$ & & \\
\hline mPAP $(m m H g) *$ & 44.50 & $39.50-47.00$ & 26.00 & $24.00-27.00$ & & \\
\hline $\mathrm{Cl}\left(\mathrm{L} / \mathrm{min} / \mathrm{m}^{2}\right)^{*}$ & 2.29 & $2.19-2.40$ & 2.51 & $2.44-2.66$ & & \\
\hline PVR (Wood units)* & 6.40 & $5.52-8.52$ & 2.80 & $2.60-3.06$ & & \\
\hline $6 m w t$ distance $(m)^{*}$ & 267 & $242-316$ & 353 & $328-380$ & & \\
\hline WHO class* & 3 & $3-3$ & 2 & $2-2$ & & \\
\hline
\end{tabular}

*Variables different between Pre and Post PEA samples.

fVariables different between Pre PEA and healthy control samples.

SVariables different between Post PEA and healthy control samples.

IL - interleukin, TNF $\alpha$ - tumour necrosis factor $\alpha$, hsCRP - high sensitivity C-reactive protein, VEGF - vascular endothelial growth factor, Ang2 - angiopoietin 2, BMP9 - bone morphogenetic protein 9, ProBNP - prohormone brain natriuretic peptide, RAP - right atrial pressure, mPAP -mean pulmonary artery pressure, $\mathrm{Cl}$ - cardiac index, PVR - pulmonary vascular resistance, 6 mwt - six minute walk test.

\section{P266 DO ENDOTHELIN-1 AND INFLAMMATION PLAY A ROLE IN AIRWAY OBSTRUCTION IN PULMONARY ARTERIAL HYPERTENSION ASSOCIATED WITH CONGENITAL HEART DISEASE?}

${ }^{1} \mathrm{AT}$ Low, ${ }^{2} \mathrm{~S} J$ George, ${ }^{2} \mathrm{AB}$ Millar, ${ }^{1} \mathrm{RMR}$ Tulloh. ${ }^{1}$ University Hospitals Bristol, Bristol, UK; ${ }^{2}$ University of Bristol, Bristol, UK

10.1136/thoraxjnl-2015-207770.402
Introduction Airway obstruction has been demonstrated in patients with Pulmonary Arterial Hypertension Associated with Congenital Heart Disease (CHD-APAH), but the cause is unknown. The vasoactive mediator endothelin-1 is a potent vasoconstrictor that induces smooth muscle proliferation in pulmonary arterial hypertension. Endothelin-1 also has the potential to cause bronchoconstriction when present in the airways, though this has not been demonstrated in CHD-

Abstract P266 Table 1 Serum and induced sputum cytokine and endothelin-1 levels for CHD-APAH patients, CHD patients and healthy controls

\begin{tabular}{|c|c|c|c|c|c|}
\hline & Analyte (pg/ml) & CHD-APAH & CHD & Healthy control & $p$ value \\
\hline \multirow[t]{7}{*}{ Serum $(n=56)$} & IL1 $\beta$ & $1(0.52-2.4)$ & $0.36(0.22-1.18)$ & $0.43(0.04-0.78)$ & $0.0214^{*}$ \\
\hline & IL6 & $2.70(1.96-3.97)$ & $1.69(1.2-1.88)$ & $1.53(1.02-1.86)$ & $0.0005^{*}$ \\
\hline & IL8 & $12.3(10.5-15.5)$ & $8.62(6.78-15.28)$ & $9.26(6.12-12.18)$ & $0.0161^{*}$ \\
\hline & IL10 & $0.71(0.26-1.01)$ & $0.65(0.54-1.18)$ & $0.47(0.18-0.76)$ & 0.1119 \\
\hline & TNF $\alpha$ & $12.9(10.82-15)$ & $11.97(9.8-14.42)$ & $10.95(7.38-12.36)$ & $0.0411^{\#}$ \\
\hline & VEGF & $78.9(47.7-101.9)$ & $89.6(58.5-115.9)$ & $41.3(27.7-72.0)$ & $0.0232^{\#}$ \\
\hline & ET-1 & $2.43(2.13-3.30)$ & $1.43(1.16-1.72)$ & $1.48(1.20-1.77)$ & $0.0001^{*}$ \\
\hline \multirow[t]{7}{*}{ Sputum $(n=30)$} & IL1 $\beta$ & $18.2(12.2-33.1)$ & $45.4(23.7-61.3)$ & $36.4(22.2-106.2)$ & 0.2126 \\
\hline & IL6 & $10.6(5.4-57.6)$ & $14.7(9.4-35.2)$ & $16.6(6.4-29.2)$ & 0.7159 \\
\hline & IL8 & $712.4(447.1-1246.4)$ & $746.0(620.5-2335.5)$ & $893.4(348.1-2780.1)$ & 0.9351 \\
\hline & IL10 & $0.64(0.46-0.9)$ & $0.74(0.6-0.9)$ & $0.6(0.44-1.5)$ & 0.6519 \\
\hline & TNF $\alpha$ & $5.89(4.56-7.92)$ & $8.36(4.66-17.7)$ & 5.09 (3.66-14.84) & 0.5719 \\
\hline & VEGF & $323.6(150.6-376.2)$ & 314.5 (196.8-464.6) & $295.7(255.6-454.4)$ & 0.9645 \\
\hline & ET-1 & $0(0-0.82)$ & $0.56(0-0.82)$ & $0.98(0.55-1.1)$ & 0.1810 \\
\hline
\end{tabular}

Data presented as median (IQR).

$P$ values calculated by Kruskal-Wallis.

*Post hoc comparison showing CHD-APAH levels significantly greater than CHD and significantly greater than healthy controls $(p<0.05)$.

"Post hoc comparison showing CHD-APAH and CHD levels significantly greater than for healthy controls $(p<0.05)$.

$\mathrm{APAH}=$ Associated pulmonary arterial hypertension, $\mathrm{CHD}=$ Congenital heart disease, $\mathrm{ET}=$ endothelin, IL $=$ interleukin, $\mathrm{TNF}=$ tumour necrosis factor, VEGF $=$ vascular endothelial growth factor. 
APAH. Systemic inflammation also occurs in CHD-APAH but associated airway inflammation has not been investigated. This study investigates the relationship between inflammation, endothelin-1 and airway dysfunction in CHD-APAH patients. Methods 58 patients were prospectively recruited: $20 \mathrm{CHD}$ APAH, $20 \mathrm{CHD}$ and 18 healthy controls. Exclusion criteria were pre-existing lung disease, significant smoking history, scoliosis and Down's syndrome. Participants performed full lung function tests and provided serum and induced sputum samples at a single visit. Serum and sputum cytokines were measured by multiplex bead assay array and endothelin-1 levels measured by enzyme linked immunosorbent assay. Induced sputum was also assessed for total and differential cell counts.

Results Serum cytokines and endothlin-1 levels were significantly elevated in patients with CHD-APAH in comparison to CHD and healthy controls (See Table 1). There were no significant differences in sputum cytokine or endothelin-1 levels between the 3 groups, with no differences in total or differential cell counts. A significant correlation between serum endothelin-1 levels and FEF25-75 was found for CHD-APAH patients $(\mathrm{r}=-0.6017, \mathrm{p}=$ 0.0083 Spearman). There were no significant correlations between measures of airway obstruction and serum cytokine levels.

Conclusions There is evidence of systemic inflammation in CHD-APAH patients but serum cytokines did not correlate with measures of airway dysfunction, and there was no evidence of airway inflammation. This suggests that inflammation does not play a role in airway obstruction in this patient group. Serum endothelin-1 is significantly elevated in CHD-APAH patients, and this did correlate with measures of airway obstruction. While elevated endothelin-1 in the pulmonary vessels may affect the adjacent airways, induced sputum endothelin-1 was not elevated. Whether serum endothelin-1 can cause bronchoconstriction without being associated with raised levels in the airways is unclear and requires further investigation.

\section{P267 THE EFFECTS OF APELIN ON SERUM NT-PROBNP LEVELS IN PULMONARY HYPERTENSION PATIENTS VERSUS CONTROLS}

GS Reid, KS Wilson, K Suveizdyte, L Brash, AJ Peacock, DJ Welsh. Scottish Pulmonary Vascular Unit, Glasgow, UK

\subsection{6/thoraxjnl-2015-207770.403}

Background Pulmonary Hypertension has a poor prognosis and therapy is limited to symptomatic relief. Apelin, a new therapy, has the potential to address the underlying pathology whilst also providing relief of symptoms. NT-proBNP a marker of disease severity is commonly used to assess treatment effect.

Aims and objectives This study aimed to investigate, for the first time, the effects of apelin on serum NT-proBNP concentration in groups of pulmonary hypertension patients and controls. The hypothesis of the study was that apelin would cause a change in NT-proBNP.

Methods Serum samples from patients recruited for a haemodynamic investigation of apelin were used. The groups studied were controls, pulmonary arterial hypertension and pulmonary hypertension due to left heart failure. In the haemodynamic study each patient was given an apelin and placebo infusion separately over a period of several minutes. Serum samples were taken pre and post infusion. NT-proBNP concentration in the samples was determined using the ABNOVA ELISA kit.
Results There was no significant change in NT-proBNP levels due to apelin infusion across all groups $(\mathrm{P}=0.830)$. On sub group analysis there was no significant change detected in any group as shown in Figure 1.

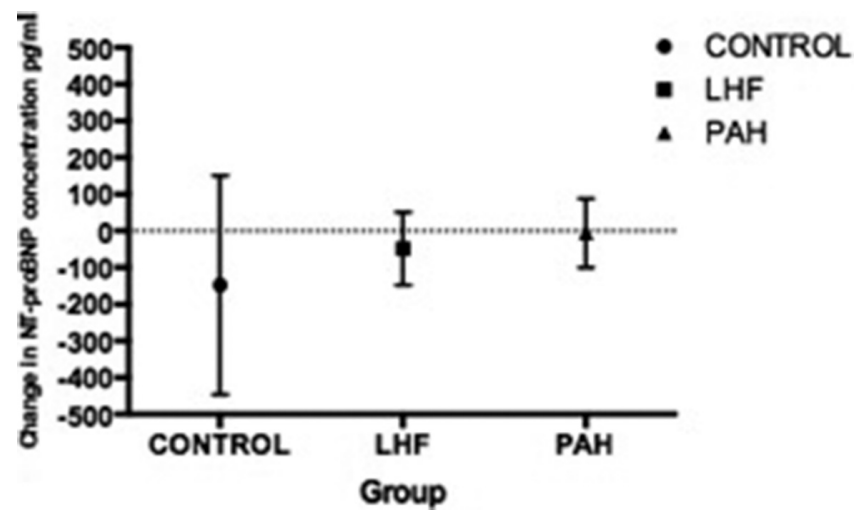

Abstract P267 Figure 1 Mean change in NT-proBNP levels post apelin infusion with $95 \%$ C.I. There was no significant change in NT-proBNP levels caused by apelin in any group

Conclusion NT-proBNP levels do not immediately change in response to several minutes of apelin infusion. This is consistent amongst control and pulmonary hypertension patients. Despite the lack of change in NT-proBNP levels seen in this study, the haemodynamic response pattern reported for apelin ${ }^{1}$ has been associated with NT-proBNP changes in other drug studies. The main difference between these studies and this study was investigation of therapy effect over a longer time period. From our results we cannot conclude that apelin has no effect on NTproBNP levels. Investigation of therapy over a longer time period is required.

\section{REFERENCE}

1 Brash L, Church C, Gibbs JS, Howard LSGE, Johnson MK, Welsh DJ, Wilkins MR, Newby DE, Peacock AJ. Apelin improves cardiac output in patients with pulmonary arterial hypertension. Submitted to ERS 2015 Conference

\section{P268 THE ROLE OF GROWTH AND DIFFERENTIATION FACTOR 15 IN SMOOTH MUSCLE CELL PROLIFERATION IN PULMONARY HYPERTENSION}

${ }^{1} \mathrm{~B}$ Garfield, ${ }^{1} \mathrm{D}$ Shao, ${ }^{2} \mathrm{~A}$ Crosby, ${ }^{2} \mathrm{P}$ Yang, ${ }^{2} \mathrm{~N}$ Morrell, ${ }^{1} \mathrm{M}$ Polkey, ${ }^{1} \mathrm{P}$ Kemp, ${ }^{1} \mathrm{~S} J$ Wort. ${ }^{1}$ Imperial College, London, UK; ${ }^{2}$ University of Cambridge, Cambridge, UK

\subsection{6/thoraxjnl-2015-207770.404}

Introduction Growth and differentiation factor 15 (GDF-15) is a prognostic marker in pulmonary hypertension ( $\mathrm{PH})$. Its effects on endothelial cells have been documented, but its mechanism of action and role in the development of $\mathrm{PH}$ have not yet been fully investigated. We aimed to define the role and mechanism of action of GDF-15 in the development of PH.

Methods Rats were treated with moncrotaline (MCT) or vehicle control and euthanized after undergoing cardiovascular monitoring 4 weeks later. The expression of GDF-15 mRNA in the lung was measured by qPCR. Total GDF-15 protein levels in serum and lung were analysed by ELISA. The distribution of GDF-15 in the lung was analysed by immunohistochemistry. GDF-15 signalling in human pulmonary artery smooth muscle cells (HPASMCs) was analysed using western blot, and its role on HPASMC proliferation was measured using a cyquant assay. 